Chander, G., Markham, B.L., Helder, D.L. (2009). Summary of Current Radiometric Calibration Coefficients for Landsat MSS, TM, ETM+, and EO-1 ALI Sensors. (In Press, Remote Sensing of Environment, Manuscript Number: RSE-D-08-00684)

\title{
Summary of Current Radiometric Calibration Coefficients for Landsat MSS, TM, ETM+, and EO-1 ALI Sensors
}

\author{
Gyanesh Chander ${ }^{a}$, Brian L. Markham ${ }^{b}$, Dennis L. Helder ${ }^{c}$ \\ "SGT, Inc.' contractor to the U.S. Geological Survey (USGS) Earth Resources Observation and Science (EROS) Center, Sioux Falls, SD \\ 57198-0001 USA. Work performed under USGS contract OBHQCN0005 Telephone: 605-594-2554, Email: gchanderoutsas. coy \\ ${ }^{\mathrm{b}}$ National Aeronautics and Space Administration (NASA) Goddard Space Flight Center (GSFC), Greenbelt, MD 20771, USA \\ "South Dakota State University (SDSU), Brookings, SD 57007, USA
}

\begin{abstract}
This paper provides a summary of the current equations and rescaling factors for converting calibrated Digital Numbers (DNs) to absolute units of at-sensor spectral radiance, Top-OfAtmosphere (TOA) reflectance, and at-sensor brightness temperature. It tabulates the necessary constants for the Multispectral Scanner (MSS), Thematic Mapper (TM), Enhanced Thematic Mapper Plus (ETM+), and Advanced Land Imager (ALI) sensors. These conversions provide a basis for standardized comparison of data in a single scene or between images acquired on different dates or by different sensors. This paper forms a needed guide for Landsat data users who now have access to the entire Landsat archive at no cost.
\end{abstract}

Keywords: Landsat, MSS, TM, ETM+, EO-1 ALI, LMIN ${ }_{\lambda}, \operatorname{LMAX}_{\lambda}$, ESUN ${ }_{\lambda}$, LPGS, NLAPS, Gain, Bias, Calibration, Spectral Radiance, Reflectance, Temperature

\section{Introduction}

The Landsat series of satellites provides the longest continuous record of satellite-based observations. As such, Landsat is an invaluable resource for monitoring global change and is a primary source of medium spatial resolution Earth observations used in decision-making (Fuller et al., 1994; Townshend et al., 1995; Goward et al., 1997; Vogelmann et al., 2001; Woodcock et al., 2001; Cohen et al., 2004; Goward et al., 2006; Masek et al., 2008; Wulder et al., 2008). To meet observation requirements at a scale revealing both natural and human-induced landscape changes, Landsat provides the only inventory of the global land surface over time on a seasonal basis (Special issues on Landsat, 1984; 1985; 1997; 2001; 2003; 2004; 2006). The Landsat Program began in early 1972 with the launch of the first satellite in the series. As technological capabilities increased, so did the amount and quality of image data captured by the various sensors onboard the satellites. Table 1 presents general information about each Landsat satellite.

Landsat satellites can be classified into three groups, based on sensor and platform characteristics. The first group consists of Landsat 1 (L1), Landsat 2 (L2), and Landsat 3 (L3), with the Multispectral Scanner (MSS) sensor and the Return Beam Vidicon (RBV) camera as payloads on a "NIMBUS-like" platform. The spatial resolution of the MSS sensor was 
approximately $79 \mathrm{~m}$ (but often processed to pixel size of $60 \mathrm{~m}$ ), with four bands ranging from the visible blue to the Near-Infrared (NIR) wavelengths. The MSS sensor on L3 included a fifth band in the thermal infrared wavelength, with a spectral range from 10.4 to $12.6 \mu \mathrm{m}$. The L1-L3 MSS sensors used a band-naming convention of MSS-4, MSS-5, MSS-6, and MSS-7 for the blue, green, red, and NIR bands, respectively (Markham \& Barker, 1983). This designation is obsolete, and to be consistent with the TM and ETM+ sensors, the MSS bands are referred to here as Bands 1-4, respectively.

The second group includes Landsat 4 (L4) and Landsat 5 (L5), which carry the Thematic Mapper (TM) sensor, as well as the MSS, on the Multimission Modular Spacecraft. This second generation of Landsat satellites marked a significant advance in remote sensing through the addition of a more sophisticated sensor, improved acquisition and transmission of data, and more rapid data processing at a highly automated processing facility. The MSS sensor was included to provide continuity with the earlier Landsat missions, but TM data quickly became the primary source of information used from these satellites because the data offered enhanced spatial, spectral, radiometric, and geometric performance over data from the MSS sensor. The TM sensor has a spatial resolution of $30 \mathrm{~m}$ for the six reflective bands and $120 \mathrm{~m}$ for the thermal band. Because there are no onboard recorders on these sensors, acquisitions are limited to real-time downlink only.

The third group consists of Landsat 6 (L6) and Landsat 7 (L7), which include the Enhanced Thematic Mapper (ETM) and the Enhanced Thematic Mapper Plus (ETM+) sensors, respectively. No MSS sensors were included on either satellite. Landsat 6 failed on launch. The L7 ETM+ sensor has a spatial resolution of $30 \mathrm{~m}$ for the six reflective bands, $60 \mathrm{~m}$ for the thermal band, and includes a panchromatic (pan) band with a $15 \mathrm{~m}$ resolution. $\mathrm{L} 7$ has a 378 gigabit (Gb) Solid State Recorder (SSR) that can hold 42 minutes (approximately 100 scenes) of sensor data and 29 hours of housekeeping telemetry concurrently (L7 Science Data User's Handbook ${ }^{1}$ ).

The Advanced Land Imager (ALI) onboard the Earth Observer-1 (EO-1) satellite is a technology demonstration that serves as a prototype for the Landsat Data Continuity Mission (LDCM). The ALI observes the Earth in 10 spectral bands; nine spectral bands have a spatial resolution of $30 \mathrm{~m}$, and a pan band has a spatial resolution of $10 \mathrm{~m}$.

The Landsat data archive at the U.S. Geological Survey (USGS) Earth Resources Observation and Science (EROS) Center holds an unequaled 36-year record of the Earth's

\footnotetext{
'http/landsathandbook gsfo nasa govhandbook html, Landsat Project Science Office, Goddard Space Flight Center.
} 
Chander, G., Markham, B.L., Helder, D.L. (2009). Summary of Current Radiometric Calibration Coefficients for

Landsat MSS, TM, ETM+, and EO-1 ALI Sensors. (In Press, Remote Sensing of Environment, Manuscript Number: RSE-D-08-00684)

surface and is available at no cost to users via the Internet (Woodcock et al., 2008). Users can access and search the Landsat data archive via the EarthExplorer $(E E)^{2}$ or Global Visualization Viewer (GloVis) ${ }^{3}$ web sites. Note that the Landsat scenes collected by locations within the International Ground Station (IGS) network may be available only from the particular station that collected the scene.

\section{Purpose}

Equations and parameters to convert calibrated Digital Numbers (DNs) to physical units, such as at-sensor radiance or Top-Of-Atmosphere (TOA) reflectance, have been presented in a "sensor-specific" manner elsewhere, e.g., MSS (Markham \& Barker, 1986, 1987; Helder, 1993), TM (Chander \& Markham, 2003; Chander et al., 2007), ETM+ (Handbook ${ }^{1}$ ), and ALI (Markham et al., 2004a). This paper, however, tabulates the necessary constants for all of the Landsat sensors in one place defined in a consistent manner and provides a brief overview of the radiometric calibration procedure summarizing the current accuracy of the at-sensor spectral radiances obtained after performing these radiometric conversions on standard data products generated by U.S. ground processing systems.

\section{Radiometric calibration procedure}

The ability to detect and quantify changes in the Earth's environment depends on sensors that can provide calibrated (known accuracy and precision) and consistent measurements of the Earth's surface features through time. The correct interpretation of scientific information from a global, long-term series of remote-sensing products requires the ability to discriminate between product artifacts and changes in the Earth processes being monitored (Roy et al., 2002). Radiometric characterization and calibration is a prerequisite for creating highquality science data, and consequently, higher-level downstream products.

\subsection{MSS sensors}

Each MSS sensor incorporates an Internal Calibrator (IC) system, consisting of a pair of lamp assemblies (for redundancy) and a rotating shutter wheel. The shutter wheel includes a mirror and a neutral density filter that varies in transmittance with rotation angle. The calibration system output appears as a light pulse at the focal plane that rises rapidly and then decays slowly. This pulse is referred to as the calibration wedge (Markham \& Barker, 1987). The radiometric calibration of the MSS sensors is performed in two stages. First, raw data from Bands 1-3 are "decompressed" or linearized and rescaled to 7 bits using fixed look-up tables. The look-

\footnotetext{
${ }^{2}$ httplearthexplorer usgs gov

${ }^{3}$ httofolous usgs.gov
} 
up tables are derived from prelaunch measurements of the compression amplifiers. Second, the postlaunch gain and offset for each detector of all four bands are individually calculated by a linear regression of the detector responses to the samples of the in-orbit calibration wedge with the prelaunch radiances for these samples. A reasonable estimate of the overall calibration uncertainty of each MSS sensor at-sensor spectral radiances is $\pm 10 \%$, which was the specified accuracy for the sensor (Markham \& Barker, 1987). In most cases, the ground processing system must apply an additional step to uncalibrate the MSS data because a number of MSS scenes were archived as radiometrically corrected products. The previously calibrated archived MSS data must be transformed back into raw DNs using the coefficients stored in the data before applying the radiometric calibration procedure. Studies are underway to evaluate the MSS calibration consistency and provide post-calibration adjustments of the MSS sensors so they are consistent over time and consistent between sensors (Helder, 2008a).

\subsection{TM sensors}

The TM sensor includes an onboard calibration system called the IC. The IC consists of a black shutter flag, three lamps, a cavity blackbody, and the optical components necessary to get the lamp and blackbody radiance to the focal plane. The lamps are used to calibrate the reflective bands, and the blackbody is used to calibrate the thermal band. Historically, the TM radiometric calibration procedure used the detector's response to the $I C$ to determine radiometric gains and offsets on a scene-by-scene basis. Before launch, the effective radiance of each lamp state for each reflective band's detector was determined such that each detector's response to the internal lamp was compared to its response to an external calibrated source. The reflective band calibration algorithm for in-flight data used a regression of the detector responses against the prelaunch radiances of the eight lamp states. The slope of the regression represented the gain, while the intercept represented the bias. This algorithm assumed that irradiance of the calibration lamps remained constant over time since launch. Any change in response was treated as a change in sensor response, and thus was compensated for during processing. On-orbit data from individual lamps indicated that the lamps were not particularly stable. Because there was no way to validate the lamp radiances once in orbit, the prelaunch measured radiances were the only metrics available for the regression procedure. Recent studies ${ }^{4}$ (Thome et al., 1997a, 1997b; Helder et al., 1998; Markham et al., 1998; Teillet et al., 2001, 2004; Chander et al., 2004) indicate that the regression calibration did not actually represent detector gains for most of the mission. However, the regression procedure was used until 2003 to generate L5 TM data products and is still used to generate L4 TM products. The calibration uncertainties of the L4 TM at-sensor

\footnotetext{
${ }^{4}$ Radiometric performance studies of the TM sensors have also led to a detailed understanding of several image artifacts due to particular sensor characteristics (Helder \& Ruggles, 2004a). These artifact corrections (such as Scan-Correlated Shift [SCS], Memory Effect [ME], and Coherent Noise [CN]), along with detector-to-detector normalization (Helder et. al., $2004 b$ ), are necessary to maintain the internal consistency of the calibration within a scene.
} 
Chander, G., Markham, B.L., Helder, D.L. (2009). Summary of Current Radiometric Calibration Coefficients for Landsat MSS. TM, ETM+, and EO-1 ALI Sensors. (in Press, Remote Sensing of Environment, Manuscript Number: RSE-D-08-00684)

spectral radiances are $\pm 10 \%$, which was the specified accuracy for the sensor (GSFC specification, 1981).

The L5 TM reflective band calibration procedure was updated in 2003 (Chander \& Markham, 2003) to remove the dependence on the changing IC lamps. The new calibration gains implemented on May 5, 2003, for the reflective bands $(1-5,7)$ were based on lifetime radiometric calibration curves derived from the detectors' responses to the IC, cross-calibration with ETM+, and vicarious measurements (Chander et al., 2004a). The gains were further revised on April 2, 2007, based on the detectors' responses to pseudo-invariant desert sites and cross-calibration with ETM+ (Chander et al., 2007). Although this calibration update applies to all archived and future L5 TM data, the principal improvements in the calibration are for data acquired during the first eight years of the mission (1984-1991), where changes in the sensor gain values are as much as $15 \%$. The radiometric scaling coefficients for Bands 1 and 2 for approximately the first eight years of the mission have also been changed. Along with the revised reflective band radiometric calibration on April 2, 2007, an sensor offset correction of $0.092 \mathrm{~W} /\left(\mathrm{m}^{2} \mathrm{sr} \mu \mathrm{m}\right)$, or about $0.68 \mathrm{~K}$ (at $300 \mathrm{~K}$ ), was added to all L5 TM thermal band (Band 6) data acquired since April 1999 (Barsi et al., 2007). The L5 TM radiometric calibration uncertainty of the at-sensor spectral radiances is around $5 \%$ and is somewhat worse for early years, when the sensor was changing more rapidly, and better for later years (Helder et al., 2008b). The L4 TM reflective bands and the thermal band on both the TM sensors continue to be calibrated using the $1 \mathrm{C}$. Further updates to improve the thermal band calibration are being investigated, as is the calibration of the L4 TM.

\subsection{ETM+ sensor}

The ETM+ sensor has three onboard calibration devices for the reflective bands: a Full Aperture Solar Calibrator (FASC), which is a white painted diffuser panel; a Partial Aperture Solar Calibrator (PASC), which is a set of optics that allows the ETM+ to image the Sun through small holes; and an IC, which consists of two lamps, a blackbody, a shutter, and optics to transfer the energy from the calibration sources to the focal plane. The ETM+ sensor has also been calibrated vicariously using Earth targets such as Railroad Valley (Thome, 2001; Thome et al., 2004) and cross-calibrated with multiple sensors (Teillet et al., 2001, 2006, 2007; Thome et al., 2003; Chander et al., 2004b, 2007b, 2008). The gain trends from the ETM+ sensor are regularly monitored on-orbit using the onboard calibrators and vicarious calibration. The calibration uncertainties of ETM+ at-sensor spectral radiances are $\pm 5 \%$. ETM+ is the most stable of the Landsat sensors, changing by no more than $0.5 \%$ per year in its radiometric calibration (Markham et al., 2004b). The ETM+ radiometric calibration procedure uses prelaunch gain coefficients populated in the Calibration Parameter File (CPF). These CPFs, issued quarterly, have both an "effective" and "version" date. The effective date of the CPF must match the acquisition date of 
the scene. A CPF version is active until a new CPF for that date period supersedes it. Data can be processed with any version of a CPF; the later versions have more refined parameters, as they reflect more data-rich post-acquisition analysis.

The ETM+ images are acquired in either a low- or high-gain state. The goal of using two gain settings is to maximize the sensors' 8-bit radiometric resolution without saturating the detectors. For all bands, the low-gain dynamic range is approximately 1.5 times the high-gain dynamic range. Therefore, low-gain mode is used to image surfaces with high brightness (higher dynamic range but low sensitivity), and high-gain mode is used to image surfaces with low brightness (lower dynamic range but high sensitivity).

All of the ETM+ acquisitions after May 31, 2003, have an anomaly caused by the failure of the Scan Line Corrector (SLC), which compensated for the forward motion of the spacecraft so that all the scans were aligned parallel with each other. The images with data loss are referred to as SLC-off images, whereas images collected prior to the SLC failure are referred to as SLC-on images (i.e., no data gaps exist). The malfunction of the SLC mirror assembly resulted in the loss of approximately $22 \%$ of the normal scene area (Storey et al., 2005). The missing data affects most of the image, with scan gaps varying in width from one pixel or less near the center of the image to 14 pixels along the east and west edges of the image, creating a repeating wedgeshaped pattern along the edges. The middle of the scene, approximately $22 \mathrm{~km}$ wide on a Level 1 product, contains very little duplication or data loss. Note that the SLC failure has no impact on the radiometric performance with the valid pixels.

\subsection{ALI sensor}

The ALI has two onboard radiometric calibration devices: a lamp-based system and a solar-diffuser with variable irradiance controlled by an aperture door. In addition to its onboard calibrators, ALI has the ability to collect lunar and stellar observations for calibration purposes. The ALI radiometric calibration procedure uses a fixed set of detector-by-detector gains established shortly after launch and biases measured shortly after each scene acquisition by closing the ALI's shutter. The calibration uncertainties of the ALI at-sensor spectral radiances are $\pm 5 \%$ (Mendenhall \& Lencioni, 2002). The ALI sensor is well-behaved and stable, with changes in the response being less than $2 \%$ per year even early in the mission, and averaging, at most, slightly more than $1 \%$ per year over the full mission (Markham et al., 2006).

\section{Conversion to at-sensor spectral radiance $\left(Q_{c a l}\right.$-to- $\left.L_{\lambda}\right)$}

Calculation of at-sensor spectral radiance is the fundamental step in converting image data from multiple sensors and platforms into a physically meaningful common radiometric scale. 
Radiometric calibration of the MSS, TM, ETM+, and ALI sensors involves rescaling the raw digital numbers $(Q)$ transmitted from the satellite to calibrated digital numbers $\left(Q_{c a l}\right)^{5}$, which have the same radiometric scaling for all scenes processed on the ground for a specific period.

During radiometric calibration, pixel values $(Q)$ from raw, unprocessed image data are converted to units of absolute spectral radiance using 32-bit floating-point calculations. The absolute radiance values are then scaled to 7-bit (MSS, $Q_{\text {calmax }}=127$ ), 8-bit (TM and ETM+, $\left.Q_{\text {calmax }}=255\right)$, and 16 -bit $\left(A L I, Q_{\text {calmax }}=32767\right)$ numbers representing $Q_{c a l}$ before output to distribution media. Conversion from $Q_{c a l}$ in Level 1 products back to at-sensor spectral radiance $\left(L_{\lambda}\right)$ requires knowledge of the lower and upper limit of the original rescaling factors. The following equation is used to perform the $Q_{\text {cal }}$-to- $L_{\lambda}$ conversion for Level 1 products:

$$
\begin{aligned}
& L_{\lambda}=\left(\frac{L M A X_{\lambda}-L M I N_{\lambda}}{Q_{c a l \max }-Q_{\text {cal } \min }}\right)\left(Q_{c a l}-Q_{\text {calmin }}\right)+L M I N_{\lambda} \\
& o r \\
& L_{\lambda}=G_{\text {rescale }} \times Q_{\text {cal }}+B_{\text {rescale }}
\end{aligned}
$$

Where:

$$
\begin{aligned}
& G_{\text {rescute }}=\frac{L M A X_{\lambda}-L M I N_{\lambda}}{Q_{\text {cal max }}-Q_{\text {cal min }}} \\
& B_{\text {rescale }}=L M I N_{\lambda}-\left(\frac{L M A X_{\lambda}-L M I N_{\lambda}}{Q_{\text {cal } \max }-Q_{\text {cal min }}}\right) Q_{\text {cal min }}
\end{aligned}
$$

Where

$L_{\lambda}=$ Spectral radiance at the sensor's aperture $\left[W /\left(\mathrm{m}^{2} \mathrm{sr} \mu \mathrm{m}\right)\right]$

$Q_{\text {cal }}=$ Quantized calibrated pixel value $[D N]$

$Q_{\text {calmin }}=$ Minimum quantized calibrated pixel value corresponding to $L M I N_{\lambda}[D N]$

$Q_{\text {calmax }}=$ Maximum quantized calibrated pixel value corresponding to $L M A X_{\lambda}[D N]$

$L M I N_{i}=$ Spectral at-sensor radiance that is scaled to $Q_{\text {calmin }}\left[W /\left(m^{2} s r \mu m\right)\right]$

$\operatorname{LMAX}_{i}=$ Spectral at-sensor radiance that is scaled to $Q_{\text {calmax }}\left[\mathrm{W} /\left(\mathrm{m}^{2} \mathrm{sr} \mu \mathrm{m}\right)\right]$

$\mathrm{G}_{\text {rescale }}=$ Band-specific rescaling gain factor $\left[\left(\mathrm{W} /\left(\mathrm{m}^{2} \mathrm{sr} \mu \mathrm{m}\right)\right) / \mathrm{DN}\right]$

$B_{\text {rescale }}=$ Band-specific rescaling bias factor $\left[\mathrm{W} /\left(\mathrm{m}^{2} \mathrm{sr} \mu \mathrm{m}\right)\right]$

Historically, the MSS and TM calibration information is presented in spectral radiance units of $\mathrm{mW} /\left(\mathrm{cm}^{2} \mathrm{sr} \mu \mathrm{m}\right)$. To maintain consistency with $\mathrm{ETM}+$ spectral radiance, units of $W /\left(\mathrm{m}^{2} \mathrm{sr}\right.$ $\mu \mathrm{m})$ are now used for MSS and TM calibration information. The conversion factor is 1:10 when

\footnotetext{
${ }^{5}$ These are the DNs that users receive with Level 1 Landsat products.
} 
Chander, G., Markham, B.L., Helder, D.L. (2009). Summary of Current Radiometric Calibration Coefficients for Landsat MSS, TM, ETM+, and EO-1 ALI Sensors. (In Press, Remote Sensing of Environment, Manuscript Number: RSE-D-08-00684)

converting from $\mathrm{mW} /\left(\mathrm{cm}^{2} \mathrm{sr} \mu \mathrm{m}\right)$ units to $\mathrm{W} /\left(\mathrm{m}^{2} \mathrm{sr} \mu \mathrm{m}\right)$. Tables $2,3,4$, and 5 summarize the spectral range, post-calibration dynamic ranges ${ }^{6}\left(\operatorname{LMIN}_{\hat{\lambda}}\right.$ and $\operatorname{LMAX}_{\lambda}$ scaling parameters and the corresponding rescaling gain $\left[\mathrm{G}_{\text {rescale }]}\right]$ and rescaling bias $\left[\mathrm{B}_{\text {rescale }}\right]$ values), and mean exoatmospheric solar irradiance $\left(E S U N_{\lambda}\right)$ for the MSS, TM, ETM+, and ALI sensors, respectively.

Tables 2-5 give the prelaunch "measured" (as-built performance) spectral ranges. These numbers are slightly different from the original filter specification. The center wavelengths are the average of the two spectral range numbers. Figures 1 and 2 show the Relative Spectral Response (RSR) profiles of the Landsat MSS (Markham \& Barker, 1983), TM (Markham \& Barker, 1986), ETM+ (Handbook ${ }^{1}$ ), and ALI (Mendenhall \& Parker, 1999) sensors measured during prelaunch characterization. The ETM+ spectral bands were designed to mimic the standard TM spectral bands 1-7. The ALI bands were designed to mimic the six standard ETM+ solar reflective spectral bands $1-5$, and 7 ; three new bands, $1 p, 4 p$, and $5 p$, were added to more effectively address atmospheric interference effects and specific applications. The ALI band numbering corresponds with the ETM+ spectral bands. Bands not present on the ETM+ sensor are given the " $p$," or prime, designation. MSS spectral bands are significantly different from TM and ETM+ spectral bands.

The post-calibration dynamic ranges are band-specific rescaling factors typically provided in the Level 1 product header file. Over the life of the Landsat sensors, occasional changes have occurred in the post-calibration dynamic range. Future changes are anticipated, especially in the MSS and TM data, because of the possible adjustment of the calibration constants based on comparisons to absolute radiometric measurements made on the ground. In some cases, the header file may have different rescaling factors than provided in the table included here. In these cases, the user should use the header file information that comes with the product.

Two processing systems will continue to generate Landsat data products: the Level 1 Product Generation System (LPGS) and the National Land Archive Production System (NLAPS). Starting December 8, 2008, all L7 ETM+ and L5 TM (except Thematic Mapper-Archive [TM-A] ${ }^{7}$ products) standard Level 1 products are processed through the LPGS, and all L4 TM and MSS

\footnotetext{
The post-calibration dynamic ranges summarized in Tables $2-5$ are only applicable to Landsat data processed and distributed by the USGS EROS Center. The IGSs may process the data differently, and these rescaling factors may not be applicable. "Special collections," such as the Multi-Resolution Land Characteristics Consortium (MRLC) or Global Land Survey (GLS), may have a different processing history, so the user needs to verify the respective product header information.

${ }^{7}$ A small number of TM scenes were archived as radiometrically corrected products known as TM-A data. The TM-A data are archived on a scene-by-scene basis (instead of intervals). The $L 4$ and L5 TM-A scenes will continue to be processed using NLAPS (with $Q_{\text {calmin }}=0$ ), which attempts to uncalibrate the previously applied calibration and generates the product using updated calibration procedures. Note that approximately $80 \mathrm{~L} 4 \mathrm{TM}$ and approximately $13,300 \mathrm{~L} 5 \mathrm{TM}$ scenes are archived as TM-A data, with acquisition dates ranging between Sept.1982 and Aug. 1990.
} 
standard Level 1 products are processed through the NLAPS. The Landsat Program is working toward transitioning the processing of all Landsat data to LPGS (Kline, personal communication). In mid-2009, the processing of L4 TM data will transition from NLAPS to LPGS. The scenes processed using LPGS include a header file (.MTL), which lists the $L M I N_{\lambda}$ and $L M A X_{\lambda}$ values but not the rescaling gain and bias numbers. The scenes processed using NLAPS include a processing history work order report (.WO), which lists the rescaling gain and bias numbers but not the $\operatorname{LMIN}_{\lambda}$ and LMAX

The sensitivity of the detector changes over time, causing a change in the detector gain applied during radiometric calibration. However, the numbers presented in Tables 2-5 are the rescaling factors, which are the post-calibration dynamic ranges. The $\operatorname{LMIN}_{\lambda}$ and $\operatorname{LMAX}_{\lambda}$ are a representation of how the output Landsat Level 1 data products are scaled in at-sensor radiance units. Generally, there is no need to change the $\operatorname{LMIN}_{\lambda}$ or $\operatorname{LMAX}_{A}$ unless something changes drastically on the sensor. Thus, there is no time dependence for any of the rescaling factors in Tables 2-5.

\section{Conversion to TOA reflectance ( $L_{\lambda}-$ to- $\left.\rho_{P}\right)$}

A reduction in scene-to-scene variability can be achieved by converting the at-sensor spectral radiance to exoatmospheric TOA reflectance, also known as in-band planetary albedo. When comparing images from different sensors, there are three advantages to using TOA reflectance instead of at-sensor spectral radiance. First, it removes the cosine effect of different solar zenith angles due to the time difference between data acquisitions. Second, TOA reflectance compensates for different values of the exoatmospheric solar irradiance arising from spectral band differences. Third, the TOA reflectance corrects for the variation in the Earth-Sun distance between different data acquisition dates. These variations can be significant geographically and temporally. The TOA reflectance of the Earth is computed according to the equation:

$$
\rho_{\lambda}=\frac{\pi \cdot L_{\lambda} \cdot d^{2}}{E S U N_{\lambda} \cdot \cos \theta_{s}}
$$

where

$\rho_{\mathrm{A}}=$ Planetary TOA reflectance [unitless]

$\pi=$ Mathematical constant approximately equal to 3.14159 [unitless]

$L_{\lambda}=$ Spectral radiance at the sensor's aperture $\left[W /\left(\mathrm{m}^{2} \mathrm{sr} \mu \mathrm{m}\right)\right]$

$d=$ Earth-Sun distance [astronomical units]

ESUN $_{\wedge}=$ Mean exoatmospheric solar irradiance $\left[\mathrm{W} /\left(\mathrm{m}^{2} \mu \mathrm{m}\right)\right]$ 
Chander, G., Markham, B.L., Helder, D.L. (2009). Summary of Current Radiometric Calibration Coefficients for Landsat MSS, TM, ETM+, and EO-1 ALI Sensors, (In Press, Remote Sensing of Environment, Manuscript Number: RSE-D-08-00684)

$\theta_{\mathrm{s}}=$ Solar zenith angle [degrees $\left.{ }^{8}\right]$

Note that the cosine of the solar zenith angle is equal to the sine of the solar elevation angle. The solar elevation angle at the Landsat scene center is typically stored in the Level 1 product header file (.MTL or .WO) or retrieved from the USGS EarthExplorer or GloVis online interfaces under the respective scene metadata (these web sites also contain the acquisition time in hours, minutes, and seconds). The reflectance calculation requires the Earth-Sun distance (d). Table 6 presents $d$ in astronomical units throughout a year generated using the Jet Propulsion Laboratory (JPL) Ephemeris ${ }^{9}$ (DE405) data. The d numbers are also tabulated in the Nautical Almanac.

The last column of Tables 2-5 summarizes solar exoatmospheric spectral irradiances $\left(E_{S U N}\right.$ ) for the MSS, TM, ETM+, and ALI sensors using the Thuillier solar spectrum (Thuillier et al., 2003). The Committee on Earth Observation Satellites (CEOS) Working Group on Calibration and Validation (WGCV) recommends ${ }^{10}$ using this spectrum for applications in optical-based Earth Observation that use an exoatmospheric solar irradiance spectrum. The Thuillier spectrum is believed to be the most accurate and an improvement over the other solar spectrum. Note that the CHKUR solar spectrum in MODTRAN 4.0 (Air Force Laboratory, 1998) was used previously for ETM+ (Handbook ${ }^{1}$ ) and TM (Chander \& Markham, 2003), whereas the Neckel and Lab (Neckel \& Lab, 1984) and Iqbal (Iqbal, 1983) solar spectrums were used for MSS and TM solar irradiance values (Markham \& Barker, 1986). The primary differences occur in Bands 5 and 7. For comparisons to other sensors, users need to verify that the same solar spectrum is used for all sensors.

\section{Conversion to at-sensor brightness temperature ( $L_{\lambda}$-to- $\left.T\right)$}

The thermal band data (Band 6 on TM and ETM+) can be converted from at-sensor spectral radiance to effective at-sensor brightness temperature. The at-sensor brightness temperature assumes that the Earth's surface is a black body (i.e., spectral emissivity is 1), and includes atmospheric effects (absorption and emissions along path). The at-sensor temperature uses the prelaunch calibration constants given in Table 7 . The conversion formula from the atsensor's spectral radiance to at-sensor brightness temperature is:

\footnotetext{
${ }^{8}$ Note that Excel, Matlab, $\mathrm{C}$, and many other software applications use radians, not degrees, to perform calculations. The conversion from degrees to radians is a multiplication factor of $\mathrm{pi} / 180$.

${ }^{3}$ hto / ssdipl hasa gov phorzons

${ }^{10}$ CEOS-recommended solar irradiance spectrum, hitp wacv ceos org
} 


$$
T=\frac{K 2}{\ln \left(\frac{K 1}{L_{\lambda}}+1\right)}
$$

where:

$\mathrm{T}=$ Effective at-sensor brightness temperature $[\mathrm{K}]$

$\mathrm{K} 2=$ Calibration constant $2[\mathrm{~K}]$

$\mathrm{K} 1=$ Calibration constant $1\left[\mathrm{~W} /\left(\mathrm{m}^{2} \mathrm{sr} \mu \mathrm{m}\right)\right]$

$L_{\lambda}=$ Spectral radiance at the sensor's aperture $\left[W /\left(m^{2} s r \mu m\right)\right]$

In = Natural logarithm

The ETM+ Level 1 product has two thermal bands, one acquired using a low gain setting (often referred to as Band $6 \mathrm{~L}$; useful temperature range of $130-350 \mathrm{~K}$ ) and the other using a high gain setting (often referred to as Band $6 \mathrm{H}$; useful temperature range of $240-320 \mathrm{~K}$ ). The noise equivalent change in temperature (NEAT) at $280 \mathrm{~K}$ for ETM+ high gain is 0.22 and for low gain is 0.28 . The TM Level 1 product has only one thermal band (there is no gain setting on the TM sensor), and the thermal band images have a useful temperature range of $200-340 \mathrm{~K}$. The NEAT at $280 \mathrm{~K}$ for L5 TM is $0.17-0.30$ (Barsi et al., 2003).

\section{Conclusion}

This paper provides equations and rescaling factors for converting Landsat calibrated DNs to absolute units of at-sensor spectral radiance, TOA reflectance, and at-sensor brightness temperature. It tabulates the necessary constants for the MSS, TM, ETM+, and ALI sensors in a coherent manner using the same units and definitions. This paper forms a needed guide for Landsat data users who now have access to the entire Landsat archive at no cost. Studies are ongoing to evaluate the MSS calibration consistency and provide post-calibration adjustments of the MSS sensors so they are consistent over time and consistent between sensors. Further updates to improve the TM and ETM+ thermal band calibration are being investigated, as is the calibration of the L4 TM.

\section{Acknowledgments}

The authors acknowledge the support of David Aaron (SDSU) for digitizing the spectral responses for the MSS sensors and Julia Barsi (SSAI) for generating the Earth-Sun distance. Special thanks are extended to a number of colleagues for reviewing drafts of this manuscript. The anonymous reviewers' comments were particularly valuable and their efforts are greatly appreciated. Any use of trade, product, or firm names is for descriptive purposes only and does not imply endorsement by the U.S. Government. 
Chander, G., Markham, B.L., Helder, D.L. (2009). Summary of Current Radiometric Calibration Coefficients for Landsat MSS, TM, ETM+, and EO-1 ALI Sensors. (in Press, Remote Sensing of Environment, Manuscript Number: RSE-D-08-00684)

\section{References}

Air Force Research Laboratory. (1998). Modtran Users Manual, Versions 3.7 and 4.0, Hanscom Air Force Base, MA.

Barsi, J.A., Schott, J.R., Palluconi, F.D., Helder, D.L., Hook, S.J., Markham, B.L., Chander, G., \& O'Donnell, E.M. (2003). Landsat TM and ETM+ thermal band calibration. Can. J. Remote Sensing, 29(2), 141153.

Barsi, J.A., Hook, S.J., Schott, J.R., Raqueno, N.G., \& Markham, B.L. (2007). Landsat-5 Thematic Mapper thermal band calibration update. IEEE Transactions on Geoscience and Remote Sensing, 44, 552555.

Chander, G. \& Markham, B.L. (2003). Revised Landsat-5 TM radiometric calibration procedures, and postcalibration dynamic ranges. IEEE Transactions on Geoscience and Remote Sensing, 41, 26742677.

Chander, G., Helder, D.L., Markham, B.L., Dewald, J., Kaita, E., Thome, K.J., Micijevic, E., \& Ruggles, T. (2004a). Landsat 5 TM on-orbit absolute radiometric performance. IEEE Transactions on Geoscience and Remote Sensing, 42, 2747-2760.

Chander, G., Meyer, D.J., \& Helder, D.L. (2004b). Cross-Calibration of the Landsat-7 ETMt and EO-1 ALI sensors. IEEE Transactions on Geoscience and Remote Sensing, 42(12), 2821-2831.

Chander, G., Markham, B.L., \& Barsi, J.A. (2007a). Revised Landsat 5 Thematic Mapper radiometric calibration. IEEE Transactions on Geoscience and Remote Sensing, 44, 490-494.

Chander, G., Angal, A., Choi, T., Meyer, D.J., Xiong, X., \& Teillet, P.M. (2007b). Cross-calibration of the Terra MODIS, Landsat-7 ETM+ and EO-1 ALI sensors using near simultaneous surface observation over Railroad Valley Playa, Nevada test site. In J. J. Butler, \& J. Xiong (Eds.), Proceedings of SPIE Conference 6677 on Earth Observing Systems XII, SPIE, Vol. 6677 (pp. 66770Y: 1-12). San Diego, CA.

Chander, G., Coan, M.J., \& Scaramuzza, P.L. (2008). Evaluation and Comparison of the IRS-P6 and the Landsat Sensors. IEEE Transactions on Geoscience and Remote Sensing, 46(1), 209-221.

Cohen, W.B., \& Goward, S.N. (2004). Landsat's role in ecological applications of remote sensing. BioScience, 54 (6), 535-545

Fuller, R.M., Groom, G.B., Jones, A.R. (1994). The land cover map of Great Britain: an automated classification of Landsat Thematic Mapper data," Photogrammetric Engineering \& Remote Sensing, vol. 60 , pp. 553-562.

Goward, S.N., \& Williams, D.L. (1997). Landsat and Earth Systems Science: Development of terrestrial monitoring. Photogrammetric Engineering and Remote Sensing, 63 (7), 887-900.

Goward, S., Irons, J., Franks, S., Arvidson, T., Williams, D., Faundeen, J. (2006). Historical record of landsat global coverage: Mission operations, NSLRSDA, and international cooperator stations. Photogrammetric Engineering and Remote Sensing, vol. 72, pp. 1155-1169.

GSFC Specification for the Thematic Mapper System and Associated Test Equipment. (Rev C., January 1981) GSFC 400-8-D-210C, NASA, Goddard Space Flight Center, Greenbelt, MD.

Helder, D.L (1993). MSS Radiometric Calibration Handbook. Report to the U.S. Geological Survey (USGS) Earth Resources Observation and Science (EROS) Center.

Helder, D.L., Boncyk, W.C., Morfitt, R. (1998). Absolute calibration of the Landsat Thematic Mapper using the internal calibrator. Proc. IGARSS, Seattle, WA, 1998, pp. 2716-2718.

Helder, D.L, \& Ruggles, T.A. (2004a). Landsat Thematic Mapper reflectiveband radiometric artifacts. IEEE Transactions on Geoscience and Remote Sensing, 44, 2704-2716. 
Chander, G., Markham, B.L., Helder, D.L. (2009). Summary of Current Radiometric Calibration Coefficients for

Landsat MSS, TM, ETM+, and EO-1 ALI Sensors. (In Press, Remote Sensing of Environment, Manuscript Number: RSE-D-08-00684)

Helder, D.L, Ruggles, T.A., Dewald, J.D., Madhavan, S. (2004b). Landsat-5 Thematic Mapper reflectiveband radiometric stability. IEEE Transactions on Geoscience and Remote Sensing, 44, 2704-2716.

Helder, D.L (2008a). Consistent Radiometric Calibration of the Historical Landsat Archive. Proceedings of PECORA. Denver, Colorado

Helder, D.L., Markham, B. L., Thome, K. J., Barsi, J. A., Chander, G., \& Malla R. (2008 b). Updated radiometric calibration for the Landsat 5 Thematic Mapper reflective bands. IEEE Transactions on Geoscience and Remote Sensing, 46(10), 3309-3325.

labal, M., 1983, Introduction to Solar Radiation (New York: Academic Press).

Markham, B.L., \& Barker, J.L. (1983). Spectral characterization of the Landsat-4 MSS sensors. Photogrammetric Engineering and Remote Sensing. 49(6), 811-833.

Markham, B. L., \& Barker, J.L., (1985). Spectral characterization of the LANDSAT Thematic Mapper sensors', International Journal of Remote Sensing, 6:(5) 697 - 716.

Markham, B.L., \& Barker, J.L. (1986). Landsat MSS and TM post-calibration dynamic ranges, exoatmospheric reflectances and at-satellite temperatures. Earth Observation Satellite Co., Lanham, MD, Landsat Tech. Note 1.

Markham, B.L., \& Barker, J.L. (1987). Radiometric properties of U.S. processed Landsat MSS Data. Remote Sensing of Environment, 22, 39-71.

Markham, B.L., Seiferth, J.C., Smid, J., Barker, J.L (1998). Lifetime responsivity behavior of the Landsat-5 Thematic Mapper. Proceedings of SPIE Conference 3427 on Earth Observing Systems, SPIE, Vol. 3427 (pp. 420-431). San Diego, CA.

Markham, B.L., Chander, G., Morfitt, R., Hollaren, D., Mendenhall, J.F., \& Ong, L. (2004a). Radiometric processing and calibration of EO-1 Advanced Land Imager data. Proceedings of PECORA 16 "Global Priorities in Land Remote Sensing". Sioux Falls, South Dakota.

Markham, B.L, Thome, K., Barsi, J., Kaita, E., Helder, D., Barker, J., \& Scaramuzza, P. (2004b). Landsat-7 ETM+ On-Orbit reflective-band radiometric stability and absolute calibration. IEEE Transactions on Geoscience and Remote Sensing, 42, 2810-2820.

Markham, B.L., Ong, L., Barsi, J.A., Mendenhall, J.A., Lencioni D.E., Helder, D.L., Hollaren, D.H., Morfitt, R.M. (2006). Radiometric calibration stability of the EO-1 Advanced Land Imager: 5 Years on-orbit. In R. Meynart, S. P. Neeck, H. Shimoda (Eds.), Proceedings of SPIE Conference 6361 on Sensors, Systems, and Next-Generation Satellites X, SPIE, Vol. 6361 (pp. 66770U: 1-12). San Diego, CA.

Masek, J. G., Vermote, Huang, C., Wolfe, R., Cohen W., Hall, F., Kutler, J., Nelson, P. (2008). North American forest disturbance mapped from a decadal Landsat record," Remote Sensing of Environment, 112, 2914-2926.

Mendenhall, J. A., \& Parker, A. C. (1999). Spectral calibration of the EO-1 Advanced Land Imager. Proceedings of SPIE Conference 3750 on Earth Observing Systems IV, SPIE, Vol. 3750, (pp. 109116), Denver, Colorado.

Mendenhall, J.A., \& Lencioni, D.E. (2002). EO-1 Advanced Land Imager On-Orbit Radiometric Calibration, International Geoscience and Remote Sensing Symposium. Toronto, Canada.

Nautical Almanac Office. The Nautical Almanac for the Year (United States Naval Observatory) (Washington, DC: U.S. Government Printing Office).

Neckel, H., and Labs, D. (1984). The solar radiation between 3300 and 12500 A. Sol. Phys., 90,205.

Roy, D., Borak, J, Devadiga, S., Wolfe, R., Zheng, M., Descloitres, J. (2002). The MODIS land product quality assessment approach, Remote Sensing of Environment, 83:62-76. 
Chander, G., Markham, B.L., Helder, D.L. (2009). Summary of Current Radiometric Calibration Coefficients for Landsat MSS, TM, ETM+, and EO-1 ALI Sensors. (In Press, Remote Sensing of Environment, Manuscript Number: RSE-D-08-00684)

Special Issue on Landsat 4 (1984). IEEE Transactions on Geoscience and Remote Sensing, GE-22 (3) 160, 51(9). Guest Editor: Solomonson, V.V.

Special Issue on Landsat Image Data Quality Analysis (LIDQA) (1985). Photogrammetric Engineering and Remote Sensing, 51(9). Guest Editors: Markham, B. L., and Barker, J.L.

Special Issue on 25th Anniversary of Landsat (1997). Photogrammetric Engineering and Remote Sensing, 63(7). Guest Editor: Salomonson, V.V.

Special Issue on Landsat 7. (2001). Remote Sensing of Environment, 78 (1-2), 1-220. Guest Editors: Goward, S.N., and Masek, J.G.

Special Issue on Synergistic Utilization of Landsat 7. (2003). Canadian Journal of Remote Sensing, 29 (2), 141-297. Guest Editor: Teillet, P.M.

Special Issue on Landsat Sensor Performance Characterization. (2004). IEEE Transactions on Geoscience and Remote Sensing, 42(12) 2687-2855. Guest Editors: Markham, B.L., Storey, J.C., Crawford, M.M., Goodenough, D.G., Irons, J.R.

Special Issue on Landsat Operations: Past, Present and Future. (2006). Photogrammetric Engineering and Remote Sensing, 72(10). Guest Editors: Williams, D.L, Goward, S.N., Arvidson, T.

Storey, J.C, Scaramuzza, P., and Schmidt, G. (2005). Landsat 7 scan line corrector-off gap filled product development. PECORA 16 Conference Proceedings, Sioux Falls, South Dakota, 23-27.

Teillet, P.M, Barker, J.L, Markham, B.L, Irish, R.R, Fedosejeves, G., \& Storey, J.C. (2001). Radiometric Cross-Calibration of the Landsat-7 ETM+ and Landsat-5 TM Sensors Based on Tandem Data Sets. Remote Sensing of Environment, 78(1-2), 39-54.

Teillet, P. M., Helder, D. L., Ruggles, T. A., Landry, R., Ahern, F. J., Higgs, N. J., et al. (2004). A Definitive Calibration Record for the Landsat-5 Thematic Mapper Anchored to the Landsat-7 Radiometric Scale. Canadian Journal of Remote Sensing, 30(4), 631-643.

Teillet, P. M., Markham, B. L., \& Irish, R. R. (2006). Landsat cross-calibration based on near simultaneous imaging of common ground targets. Remote Sensing of Environment, 102(3-4), 264-270.

Teillet, P.M., Fedosejevs, G., Thome, K.J., \& Barker, J.L. (2007). Impacts of spectral band difference effects on radiometric cross-calibration between satellite sensors in the solar-reflective spectral domain. Remote Sensing of Environment, 110, 393-409.

Thome, K.J., Markham, B.L., Barker, J.L., Slater, P.L., Biggar, S. (1997a). Radiometric calibration of Landsat. Photogramm. Eng. Remote Sens., vol. 63, pp. 853-858.

Thome, K. J., Crowther, B. G., \& Biggar, S. F. (1997b). Reflectance- and Irradiance-Based Calibration of Landsat-5 Thematic Mapper. Canadian Journal of Remote Sensing, 23, 309-317.

Thome, K.J. (2001). Absolute Radiometric Calibration of Landsat 7 ETM+ Using the Reflectance-Based Method. Remote Sensing of Environment, 78(1-2), 27-38.

Thome, K. J., Biggar, S. F., \& Wisniewski, W. (2003). Cross Comparison of EO-1 Sensors and Other Earth Resources Sensors to Landsat-7 ETM+ Using Railroad Valley Playa. IEEE Transactions on Geoscience and Remote Sensing, 41, 1180-1188.

Thome, K.J., Helder, D.L., Aaron, D.A., \& Dewald, J. (2004). Landsat 5 TM and Landsat-7 ETM+ Absolute Radiometric Calibration using Reflectance Based Method. IEEE Transactions on Geoscience and Remote Sensing, 42(12), 2777- 2785.

Thuillier, G., Herse, M., Labs, S., Foujols, T., Peetermans, W., Gillotay, D., Simon, P.C., Mandel, H. (2003). The Solar Spectral Irradiance from 200 to $2400 \mathrm{~nm}$ as Measured by SOLSPEC Spectrometer from the ATLAS 123 and EURECA Missions. Solar Physics, Solar Physics, v. 214, Issue 1, p. 1-22. 
Chander, G., Markham, B.L., Helder, D.L. (2009). Summary of Current Radiometric Calibration Coefficients for

Landsat MSS, TM, ETM+, and EO-1 ALI Sensors. (In Press, Remote Sensing of Environment, Manuscript Number: RSE-D-08-00684)

Townshend, J.R.G., Bell, V., Desch, A.C., Havlicek, C., Justice, C.O., Lawrence, W.E., Skole, D., Chomentowski, W.W., Moore, B., Salas, W., Tucjer, C.J. (1995). The NASA Landsat Pathfinder Humid Tropical Deforestation Project. In Proceedings Land Satellite Information in the Next Decade, ASPRS Conference, (pp. 76-87). Vienna, Virginia

Vogelmann, J.E., Howard, S.M., Yang, L., Larson, C.R., Wylie, B.K., Van Driel, J.N. (2001). Completion of the 1990's National Land Cover Data Set for the conterminous United States," Photogrammetric Engineering and Remote Sensing, vol. 67, pp. 650-662.

Woodcock, C.E., Macomber, S.A., Pax-Lenney, M., Cohen, W.C. (2006). Monitoring large areas for forest change using Landsat: Generalization across space, time and Landsat sensors. Remote Sensing of Environment, 78, 194-203.

Woodcock, C.E., Allen, A.A., Anderson, M., Belward, A.S., Bindschadler, R., Cohen, W.B., Gao, F., Goward, S.N., Helder, D., Helmer, E., Nemani, R., Oreapoulos, L., Schott, J., Thenkabail, P.S., Vermote, E.F., Vogelmann, J., Wulder, M.A., Wynne, R. , 2008, Free access to Landsat imagery, Science, $320: 1011$.

Wulder, M.A., White, J.C., Goward, S.N., Masek, J.G., Irons, J.R., Herold, M., Cohen, W.B., Loveland, T.R., Woodcock, C. E. (2008). Landsat continuity: Issues and opportunities for land cover monitoring. Remote Sensing of Environment, 112, 955-969. 
Chander, G., Markham, B.L., Helder, D.L. (2009). Summary of Current Radiometric Calibration Coefficients for Landsat MSS, TM, ETM+, and EO-1 ALI Sensors. (In Press, Remote Sensing of Environment, Manuscript Number: RSE-0-08-00684)

Table 1

Landsat satellites launch dates

\begin{tabular}{|c|c|c|c|c|c|c|c|c|}
\hline Satellite & Sensors & Launch Date & Decommission & Altituile & Inclination & Perlad & Repeat cycle & Cossing \\
\hline & & & & $\mathrm{km}$ & dearees & miln & days & time (a.m.j \\
\hline Landsat I & MSS and RBV & July 23,1972 & January 7,1978 & 920 & 9920 & 103.34 & 18 & 930 \\
\hline Landsat 2 & MSS and RBV & January 22,1975 & February 25,1982 & 920 & 99.20 & 103.34 & 18 & 930 \\
\hline Landsat 4 & MSS and TM & July 16,1982 & June 30,2001 & 705 & 98.20 & 98.20 & 16 & 9.45 \\
\hline Landsat 5 & MSS and TM & March 1, 1984 & Operational & 705 & 98.20 & 98.20 & 16 & $9: 45$ \\
\hline Landsat 6 & ETM & October 5,1993 & Did not achieve arbit & & & & & \\
\hline$E 0.1$ & $\mathrm{ALI}$ & November 21,2000 & Operational & 705 & 98.20 & 98.20 & 16 & 1001 \\
\hline
\end{tabular}

Table 2

MSS spectral range, post-calibration dynamic ranges, and mean exoatmospheric solar irradiance $\left(\right.$ ESUN $_{\Lambda}$ )

\begin{tabular}{|c|c|c|c|c|c|c|c|}
\hline \multicolumn{8}{|c|}{ MSS Sensors $\left(Q_{\text {calmin }}=0\right.$ and $\left.Q_{\text {calmax }}=127\right)$} \\
\hline Band & $\begin{array}{l}\text { Spectial } \\
\text { Range }\end{array}$ & $\begin{array}{c}\text { Center } \\
\text { Wavelength }\end{array}$ & $\operatorname{LMIN}_{\boldsymbol{h}}$ & $\operatorname{LMAX}_{\hbar}$ & Grezcale & B reacile & ESUN \\
\hline Units & \multicolumn{2}{|c|}{$\mu \mathrm{III}$} & \multicolumn{2}{|c|}{$W\left(m^{2}\right.$ si $\left.\mu m\right)$} & $\left(\mathrm{Wm}^{2}\right.$ sr umi $\mathrm{DN}$ & $W\left(m^{2}\right.$ si $\left.11 m\right)$ & $W\left(m^{2} \cdot \mu m\right)$ \\
\hline \multicolumn{8}{|c|}{ L1 MSS (NLAPS) } \\
\hline 1 & $0.499-0.597$ & 0.548 & 0 & 248 & 1.952760 & 0 & 1823 \\
\hline 2 & $0.603-0.701$ & 0.652 & 0 & 200 & 1.574800 & 0 & 1559 \\
\hline 3 & $0.694-0.800$ & 0.747 & 0 & 176 & 1.385830 & 0 & 1276 \\
\hline 4 & $0.810-0.989$ & 0.900 & 0 & 153 & 1.204720 & 0 & 880.1 \\
\hline \multicolumn{8}{|c|}{ L2 MSS (NLAPS) } \\
\hline 1 & $0.497-0.598$ & 0.548 & 8 & 263 & 2.007870 & 8 & 1829 \\
\hline 2 & $0.607-0.710$ & 0.659 & 6 & 176 & 1.338580 & 6 & 1539 \\
\hline 3 & $0.697-0.802$ & 0.750 & 6 & 152 & 1.149610 & 6 & 1268 \\
\hline 4 & $0.807-0.990$ & 0899 & 3.66667 & 130.333 & 0.997373 & 3.66667 & 886.6 \\
\hline \multicolumn{8}{|c|}{ L3 MSS (NLAPS) } \\
\hline 1 & $0.497-0.593$ & 0.545 & 4 & 259 & 2.007870 & 4 & 1839 \\
\hline 2 & $0.606-0.705$ & 0.656 & 3 & 179 & 1.385830 & 3 & 1555 \\
\hline 3 & $0.693-0.793$ & 0.743 & 3 & 149 & 1.149610 & 3 & 1291 \\
\hline 4 & $0.812-0.979$ & 0.896 & 1 & 128 & 1.000000 & 1 & 887.9 \\
\hline \multicolumn{8}{|c|}{ L4 MSS (NLAPS) } \\
\hline 1 & $0495-0.605$ & 0.550 & 4 & 238 & 1.842520 & 4 & 1827 \\
\hline 2 & $0.603-0.696$ & 0.650 & 4 & 164 & 1.259840 & 4 & 1569 \\
\hline 3 & $0.701-0.813$ & 0.757 & 5 & 142 & 1.078740 & 5 & 1260 \\
\hline 4 & $0.808-1.023$ & 0.916 & 4 & 116 & 0.881890 & 4 & 866.4 \\
\hline \multicolumn{8}{|c|}{ L5 MSS (NLAPS) } \\
\hline 1 & $0.497-0.607$ & 0.552 & 3 & 268 & 2.086610 & $\overline{3}$ & 1824 \\
\hline 2 & $0.603-0.697$ & 0.650 & 3 & 179 & 1.385830 & 3 & 1570 \\
\hline 3 & $0.704-0.814$ & 0.759 & 5 & 148 & 1.125980 & 5 & 1249 \\
\hline 4 & $0.809-1.036$ & 0.923 & 3 & 123 & 0.944882 & 3 & 853.4 \\
\hline ste $1: \ln s$ & cases, the header & may have dift & nt rescali & y factor & $n$ provided here. In & e cases, the & $\begin{array}{l}\text { should } \\
\text { ary of the } \\
\text { he ground }\end{array}$ \\
\hline
\end{tabular}


Chander, G., Markham, B.L., Helder, D.L. (2009). Summary of Current Radiometric Calibration Coefficients for

Landsat MSS, TM, ETM+, and EO-1 ALI Sensors. (In Press, Remote Sensing of Enviranment, Manuscript Number: RSE-D-08-00684)

Table 3

TM spectral range, post-calibration dynamic ranges, and mean exoatmospheric solar irradiance $\left(\mathrm{ESUN}_{\Lambda}\right)$

\begin{tabular}{|c|c|c|c|c|c|c|c|}
\hline \multicolumn{8}{|c|}{$T M$ Sensors $\left(Q_{\text {calmin }}=1\right.$ and $\left.Q_{\text {calmax }}=255\right)$} \\
\hline Band & $\begin{array}{l}\text { Spectial } \\
\text { Range }\end{array}$ & $\begin{array}{c}\text { Center } \\
\text { Wavelength }\end{array}$ & $\mathbf{L M I N}_{\mathrm{h}}$ & $\operatorname{LMAX}_{i}$ & $\mathrm{G}_{\text {rescale }}$ & B rescale & ESUN $_{4}$ \\
\hline Units & \multicolumn{2}{|c|}{ Im } & \multicolumn{2}{|c|}{$W\left(m^{2}\right.$ si $\left.\mu m\right)$} & $\left(\mathrm{Wm}^{2}\right.$ sr $\left.\mu \mathrm{m}\right)$ DN & $W\left(m^{2}\right.$ sI $\left.\mu m\right)$ & $W\left(m^{2}+\mu m\right)$ \\
\hline \multicolumn{8}{|c|}{ L4 TM (NLAPS) } \\
\hline 1 & $0.452-0.518$ & 0.485 & -1.52 & 152.10 & 0.602431 & -1.52 & 1983 \\
\hline 2 & $0.529-0.609$ & 0.569 & -2.84 & 296.81 & 1.175098 & -2.84 & 1795 \\
\hline 3 & $0.624-0.693$ & 0.659 & -1.17 & 204.30 & 0.805765 & -1.17 & 1539 \\
\hline 4 & $0.776-0.905$ & 0.841 & -1.51 & 206.20 & 0.814549 & -1.51 & 1028 \\
\hline 5 & $1.568-1.784$ & 1.676 & -0.37 & 27.19 & 0.108078 & -0.37 & 219.8 \\
\hline 6 & $10.42-11.66$ & 11.040 & 1.2378 & 15.3032 & 0.055158 & 1.2378 & $N / A$ \\
\hline 7 & $2.097-2.347$ & 2.222 & -0.15 & 14.38 & 0.056980 & -0.15 & 83.49 \\
\hline \multicolumn{8}{|c|}{ L4 TM (LPGS) } \\
\hline 1 & $0452-0518$ & 0.485 & -152 & 163 & 054717 & 217 & \multirow{2}{*}{1983} \\
\hline & & 0.485 & -1.52 & 171 & 0.679213 & -2.20 & \\
\hline 2 & $0.529-0.609$ & 0.569 & -2.84 & 336 & 1.334016 & -4.17 & 1795 \\
\hline 3 & $0.624-0.693$ & 0.659 & -1.17 & 254 & 1.004606 & -2.17 & 1539 \\
\hline 4 & $0.776-0.905$ & 0.841 & -1.51 & 221 & 0.876024 & -2.39 & 1028 \\
\hline 5 & $1.568-1.784$ & 1676 & -0.37 & 31.4 & 0.125079 & -0.50 & 219.8 \\
\hline 6 & $10.42-11.66$ & 11.040 & 1.2378 & 15.3032 & 0.055376 & 1.2378 & $N / A$ \\
\hline 7 & $2.097-2.347$ & 2.222 & -0.15 & \begin{tabular}{|l|}
16.6 \\
\end{tabular} & 0.065945 & -0.22 & 83.49 \\
\hline \multicolumn{8}{|c|}{ L5 TM (LPGS) } \\
\hline \multirow{2}{*}{1} & \multirow{2}{*}{$0.452-0.518$} & \multirow{2}{*}{0.485} & -152 & 169 & 0671399 & -219 & \multirow{2}{*}{1983} \\
\hline & & & -1.52 & 193 & 0.765827 & -2.29 & \\
\hline \multirow{2}{*}{2} & \multirow{2}{*}{$0.528-0.609$} & \multirow{2}{*}{0.569} & -2.84 & 333 & 1.322205 & -416 & \multirow{2}{*}{1796} \\
\hline & & & -2.84 & 365 & 1.448189 & -4.29 & \\
\hline 3 & $0.626-0.693$ & 0.660 & -1.17 & 264 & 1.043976 & -2.21 & 1536 \\
\hline 4 & $0.776-0.904$ & 0.840 & -1.51 & 221 & 0.876024 & -2.39 & 1031 \\
\hline 5 & $1.567-1.784$ & 1.676 & -0.37 & 30.2 & 0.120354 & -0.49 & 220.0 \\
\hline 6 & $10.45-12.42$ & 11.435 & 1.2378 & 15.3032 & 0.055376 & 1.18 & N/A \\
\hline 7 & $2.097-2.349$ & 2.223 & -0.15 & 16.5 & 0.065551 & -0.22 & 83.44 \\
\hline \multicolumn{8}{|c|}{ Note 1: The $Q_{\text {eamin }}=0$ for data processed using NLAPS. The $Q_{c \text { calmin }}=1$ for data processed using LPGS. } \\
\hline \multicolumn{8}{|c|}{$\begin{array}{l}\text { Note } 2 \text { : The LMiN, is typically set to a small negative number, so a "zero radiance" target will be scaled to a snall positive DN value, } \\
\text { even in the presence of sensor noise (typically } 1 \text { DN or less [1 sigma]). This value is usually not changed throughout the mission. }\end{array}$} \\
\hline \multicolumn{8}{|c|}{ 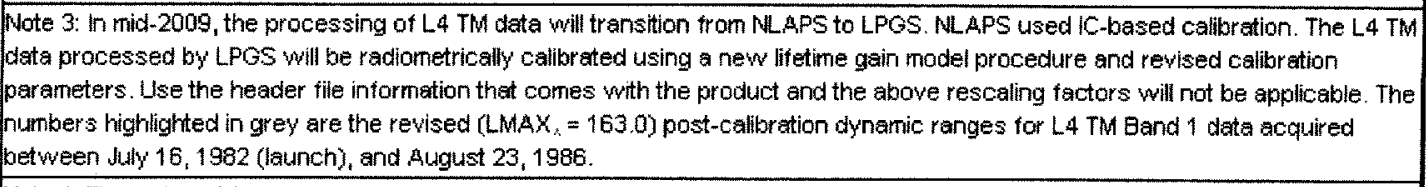 } \\
\hline \multicolumn{8}{|c|}{$\begin{array}{l}\text { Note 4: The radionetric scaling coefficients for } L 5 \text { TM Eands } 1 \text { and } 2 \text { for approximately the first eight years (1984-1991) of the } \\
\text { mission were changed to optimize the dynamic range and better preserve the sensitivity of the early mission data. The numbers } \\
\text { highlighted in grey are the revised ( } L M A X,=169.0,333.0 \text { ) post-calibration dynanic ranges for } L 5 \text { TM Band } 182 \text { data acquired } \\
\text { between March } 1,1984 \text { (launch), and December } 31,1991 \text { (Chander et al., 2007a). }\end{array}$} \\
\hline
\end{tabular}


Chander, G., Markham, B.L., Helder, D.L. (2009). Summary of Current Radiometric Calibration Coefficients for Landsat MSS, TM, ETM+, and EO-1 ALI Sensors. (In Press, Remote Sensing of Environment, Manuscript Number: RSE-D-08-00684)

Table 4

ETM+ spectral range, post-calibration dynamic ranges, and mean exoatmospheric solar irradiance $\left(\mathrm{ESUN}_{\lambda}\right)$

\begin{tabular}{|c|c|c|c|c|c|c|c|}
\hline \multicolumn{8}{|c|}{$L 7 E T M+$ Sensor $\left(Q_{\text {calmin }}=1\right.$ and $\left.Q_{c a l m a x}=255\right)$} \\
\hline & & & -ow G & in ILPE & & & \\
\hline Band & $\begin{array}{l}\text { Spectral } \\
\text { Range }\end{array}$ & $\begin{array}{c}\text { Center } \\
\text { Wavelength }\end{array}$ & $\operatorname{LMIN}_{\mathrm{X}}$ & $\operatorname{LMAX}_{\mathrm{in}}$ & Grescale & B & $E_{S U N}$ \\
\hline Units & \multicolumn{2}{|c|}{ } & \multicolumn{2}{|c|}{$W\left(m^{2}\right.$ sr $\left.\mu m\right)$} & $\left(\mathrm{W} \mathrm{m}^{2}\right.$ sI $\left.\mu \mathrm{m}\right) \mathrm{DN}$ & $W\left(m^{2}\right.$ si $\left.\mu m\right)$ & $\mathrm{W}\left(\mathrm{m}^{2} \cdot \mathrm{m}\right)$ \\
\hline 1 & $0.452-0.514$ & 0.483 & -6.2 & 293.7 & 1.180709 & $\begin{array}{l}-7.38 \\
\end{array}$ & 1997 \\
\hline 2 & $0.519-0.601$ & 0.560 & -6.4 & 300.9 & 1.209843 & -7.61 & 1812 \\
\hline 3 & $0.631-0.692$ & 0.662 & -5.0 & 234.4 & 0.942520 & -5.94 & 1533 \\
\hline 4 & $0.772-0.898$ & 0.835 & -5.1 & 241.1 & 0.969291 & -6.07 & 1039 \\
\hline 5 & $1.547-1.748$ & 1.648 & -1.0 & 47.57 & 0.191220 & -1.19 & 230.8 \\
\hline 6 & $10.31-12.36$ & 11.335 & 0.0 & 17.04 & 0.067087 & -0.07 & $N / A$ \\
\hline 7 & $2.065-2.346$ & 2.206 & -0.35 & 16.54 & 0.066496 & -0.42 & 84.90 \\
\hline PAN & $0.515-0.896$ & 0.706 & -4.7 & 243.1 & 0.975591 & -5.68 & 1362 \\
\hline \multicolumn{8}{|c|}{ High Gain (LPGS) } \\
\hline Band & $\begin{array}{l}\text { Spectial } \\
\text { Range }\end{array}$ & $\begin{array}{c}\text { Center } \\
\text { Wavelength }\end{array}$ & LMIN & $\operatorname{LMAX}_{h}$ & $G_{\text {rascale }}$ & $B_{\text {rescale }}$ & $\mathrm{ESUN}_{\mathrm{h}}$ \\
\hline Units & \multicolumn{2}{|c|}{$\mu \mathrm{m}$} & \multicolumn{2}{|c|}{$W\left(\mathrm{~m}^{2}\right.$ si $\left.\mu \mathrm{m}\right)$} & $\mathrm{W} / \mathrm{m}^{2}$ sr $\mu \mathrm{m} \mathrm{DN}$ & $W\left(m^{2}\right.$ si $\left.\mu m\right)$ & $W\left(m^{2}, \mu m\right)$ \\
\hline 1 & $0.452-0.514$ & 0.483 & -6.2 & 191.6 & 0.778740 & -6.98 & 1997 \\
\hline 2 & $0.519-0.601$ & 0.560 & .6 .4 & 196.5 & 0.798819 & -7.20 & 1812 \\
\hline 3 & $0.631-0.692$ & 0.662 & -5.0 & 152.9 & 0.621654 & -5.62 & 1533 \\
\hline 4 & $0.772-0.898$ & 0.835 & -5.1 & 157.4 & 0.639764 & -5.74 & 1039 \\
\hline 5 & $1.547-1.748$ & 1.648 & -1.0 & 31.06 & 0.126220 & -1.13 & 230.8 \\
\hline 6 & $10.31-12.36$ & 11.335 & 3.2 & 12.65 & 0.037205 & 3.16 & $N / A$ \\
\hline 7 & $2.065-2.346$ & 2.206 & -0.35 & 10.80 & 0.043898 & -0.39 & 84.90 \\
\hline PAN & $0.515-0.896$ & 0.706 & -4.7 & 158.3 & 0.641732 & .5 .34 & 1362 \\
\hline
\end{tabular}


Chander, G., Markham, B.L., Heider, D.L. (2009). Summary of Current Radiometric Calibration Coefficients for Landsat MSS, TM, ETM+, and EO-1 ALI Sensors. (In Press, Remote Sensing of Environment, Manuscript Number: RSE-D-08-00684)

Table 5

ALI spectral range, post-calibration dynamic ranges, and mean exoatmospheric solar irradiance $\left(\right.$ ESUN $_{\lambda}$ ). All EO-1 ALI standard Level 1 products are processed through the EO-1 Product Generation System (EPGS).

\begin{tabular}{|c|c|c|c|c|c|c|c|}
\hline \multicolumn{8}{|c|}{ E0-1 ALI Sensor $\left(Q_{\text {calmin }}=1\right.$ and $\left.Q_{\text {calmax }}=32767\right)$} \\
\hline Band & $\begin{array}{l}\text { Spectral } \\
\text { Range }\end{array}$ & $\begin{array}{c}\text { Center } \\
\text { Wavelength }\end{array}$ & LMIN $_{h}$ & LMAX & Grescale & B rescale & ESUN \\
\hline Units & \multicolumn{2}{|c|}{ IIIII } & \multicolumn{2}{|c|}{$W\left(m^{2}\right.$ sr $\left.\mu m\right)$} & $\left(\mathrm{Wim}^{2}\right.$ st $\left.\mu \mathrm{m}\right)$ oN & W: $\left(\mathrm{m}^{2}\right.$ si $\left.\mu \mathrm{ml}\right)$ & $W\left(m^{2}, \mu m\right)$ \\
\hline PAN & $0.480-0.690$ & 0.585 & -2.18 & 784.2 & 0.024 & -2.2 & 1724 \\
\hline 1P & $0.433-0.453$ & 0.443 & -3.36 & 1471 & 0045 & -3.4 & 1857 \\
\hline 1 & $0.450-0.515$ & 0.483 & -4.36 & 1405 & 0.043 & -4.4 & 1996 \\
\hline 2 & $0.525-0.605$ & 0.565 & -1.87 & 915.5 & 0.028 & -1.9 & 1807 \\
\hline 3 & $0.633-0.690$ & 0.662 & -1.28 & 588.5 & 0.018 & -1.3 & 1536 \\
\hline 4 & $0.775-0.805$ & 0.790 & -0.84 & 359.6 & 0.011 & -0.85 & 1145 \\
\hline 4P & $0.845-0.890$ & 0.868 & -0.641 & 297.5 & 0.0091 & -0.65 & 955.8 \\
\hline $5 P$ & $1.200-1.300$ & 1.250 & -1.29 & 270.7 & 0.0083 & -1.3 & 452.3 \\
\hline 5 & $1.550-1.750$ & 1.650 & -0.597 & 91.14 & 0.0028 & -0.6 & 235.1 \\
\hline 7 & $2.080-2.350$ & 2.215 & -0.209 & 29.61 & 0.00091 & -0.21 & 8238 \\
\hline
\end{tabular}


Chander, G., Markham, B.L., Helder, D.L. (2009). Summary of Current Radiometric Calibration Coefficients for

Landsat MSS, TM, ETM+, and EO-1 ALI Sensors. (In Press, Remote Sensing of Environment, Manuscript Number: RSE+D-08-00684)

Table 6

Earth-Sun distance (d) in astronomical units for Day of the Year (DOY)

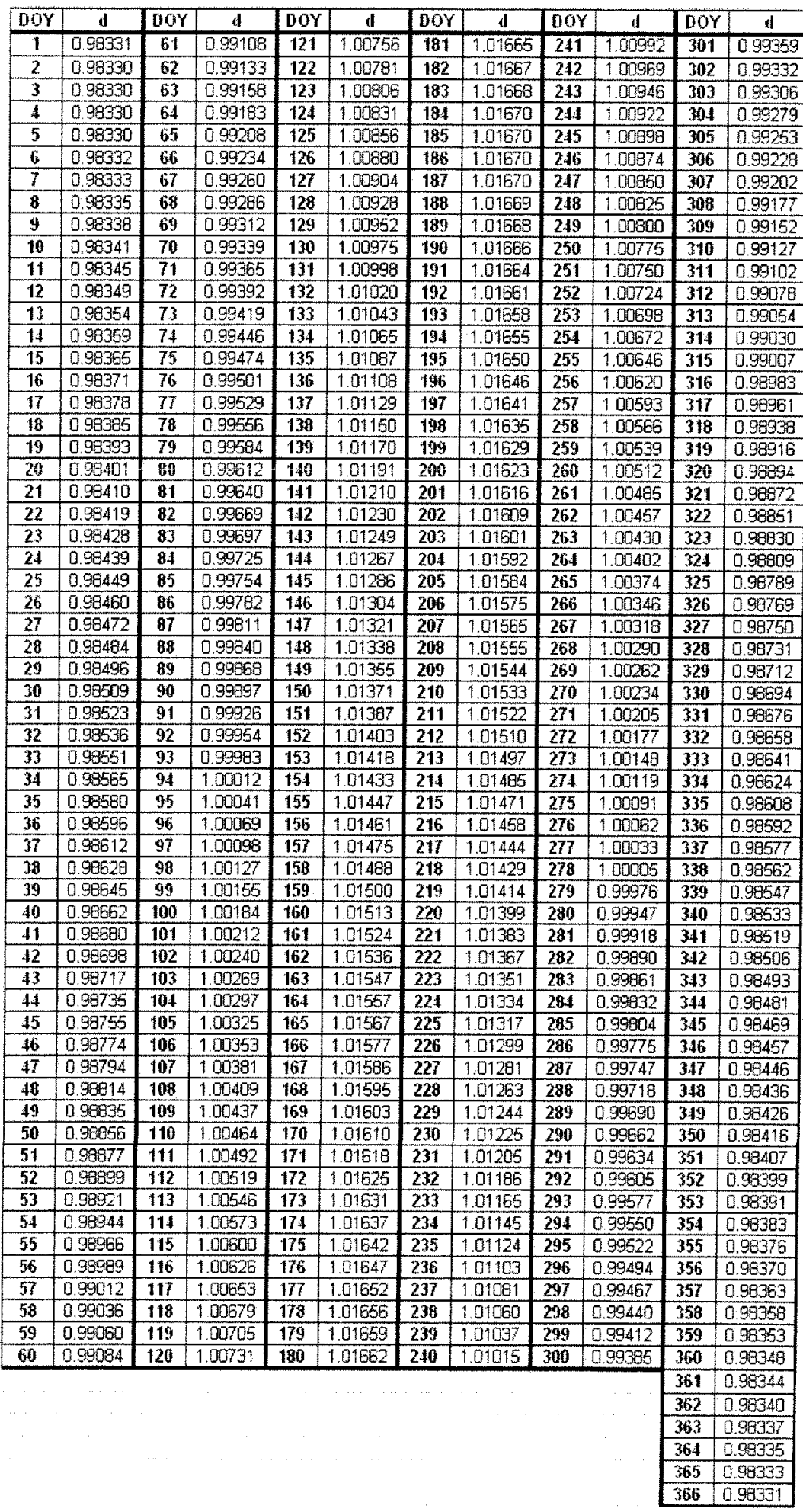


Chander, G. Markham, B.L., Helder, D.L. (2009), Summary of Current Radiometric Calibration Coefficients for

Landsat MSS, TM, ETM+, and EO-1 ALI Sensors. (in Press, Remote Sensing of Environment, Manuscript Number: RSE-D-08-00684)

Table 7

TM and ETM+ thermal band calibration constants

\begin{tabular}{|c|c|c|}
\hline Constant & K1 & K2 \\
\hline Units & W $\left(\mathbf{m}^{2} \mathbf{s r} \boldsymbol{\mu m}\right)$ & Kelvin \\
\hline L4 TM & 671.62 & 1284.30 \\
\hline L5 TM & 607.76 & 1260.56 \\
\hline L7 ETM+ & 666.09 & 1282.71 \\
\hline
\end{tabular}


Chander, G., Markham, B.L., Helder, D.L. (2009). Summary of Current Radiametric Calibration Coefficients for Landsat MSS, TM, ETM+, and EO-1 ALI Sensors. (In Press, Remote Sensing of Environment, Manuscript Number; RSE-D-08-00684)

\section{Appendix}

Table A1

To maintain consistency, all Landsat scenes are based on the following naming convention

\begin{tabular}{|c|c|}
\hline $\begin{array}{l}\text { Format Example: } \\
\text { LXSPPPRRRYYYYDDGSIVV } \\
L=\text { Landsat } \\
X=\text { Sensor } \\
\text { S = Satellite } \\
\text { PPP = Worldwide Reference System (WRS) } \\
\text { Path } \\
\text { RRR = WRS Row } \\
\text { YYYY = Year } \\
\text { DDD = Julian Day of Year } \\
\text { GSI = Ground Station Identifier } \\
\text { WV = Version }\end{array}$ & $\begin{array}{l}\text { Sensor Examples: } \\
\text { LM10170391976031AAA01 (MSS) } \\
\text { LT40170361982320XXX08 (TM) } \\
\text { LE70160392004262EDC02 (ETM+) }\end{array}$ \\
\hline \multicolumn{2}{|c|}{ "Ground Stations Identifiers - Data received at these sites are held at EROS } \\
\hline $\begin{array}{l}\text { AAA = North American site unknown } \\
\text { ASA = Alice Springs, Australia } \\
\text { FUI = Fucino, Italy (Historical) } \\
\text { GLC = Gilmore Creek, AK, US } \\
\text { HOA = Hobart, Australia } \\
\text { KIS = Kiruna, Sweden } \\
\text { MTI = Matera, Italy } \\
\text { EDC = Receiving site unknown } \\
\text { PAC = Prince Albert, Canada }\end{array}$ & $\begin{array}{l}\text { GNC = Gatineau, Canada } \\
\text { LGS = EROS, SD, USA, Landsat } 5 \text { data } \\
\text { acquired by EROS beginning July 1,2001 } \\
\text { MOR = Moscow, Russia } \\
\text { MLK = Malinda, Kenya } \\
\text { IKR = Irkutsk, Russia } \\
\text { CHM = Chetumal, Mexico } \\
\text { XXO = Receiving site unknown } \\
\text { XXX = Receiving site unknown }\end{array}$ \\
\hline
\end{tabular}

Table A2

Standard Level 1 product specifications

Product Type - Level 1T (Terrain Corrected)

Pixel Size - 15/30/60 meters

Output format - GeoTIFF

Resampling Method - Cubic Convolution (CC)

Map Projection - Universal Transverse Mercator (UTM)

Polar Stereographic for Antarctica

Image Orientation - Map (North Up)

Distribution - File Transfer Protocol (FTP) Download only 
Chander, G. Markham, B.L., Helder, D.L. (2009). Summary of Current Radiometric Calibration Coefficients for Landsat MSS, TM, ETM+, and EO-1 ALI Sensors. (In Press, Remote Sensing of Environment, Manuscript Number: RSE-D-08-00684)
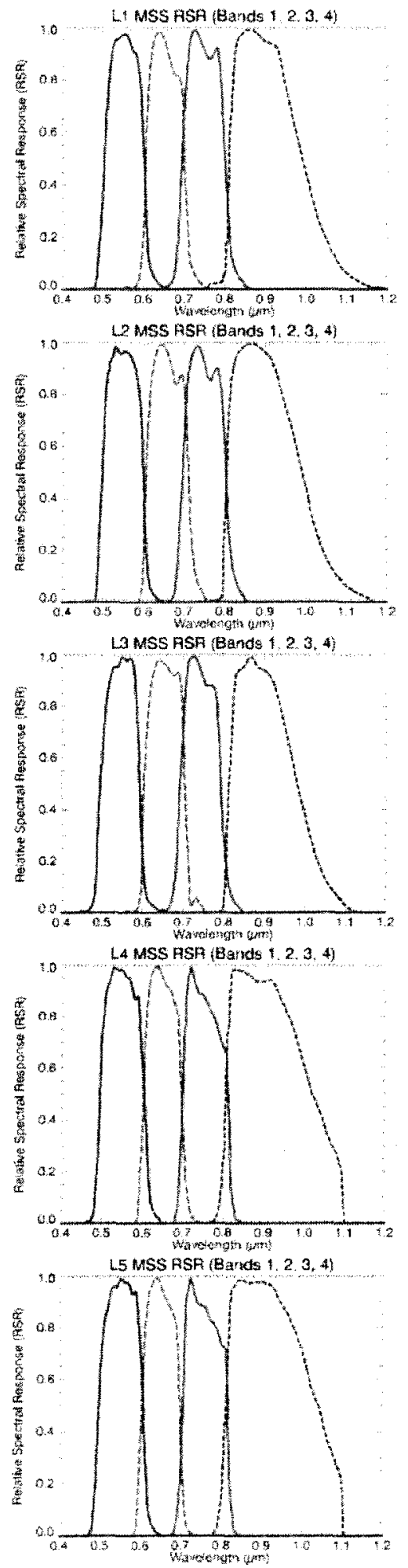

Fig. 1. Comparison of the solar reflective bands RSR profiles of L1-5 MSS sensors. 
Chander, G., Markham, B.L., Helder, D.L. (2009). Summary of Current Radiometric Calibration Coefficients for Landsat MSS, TM, ETM+, and EO-1 ALI Sensors. (In Press, Remote Sensing of Environment, Manuscript Number: RSE-D-08-00684)
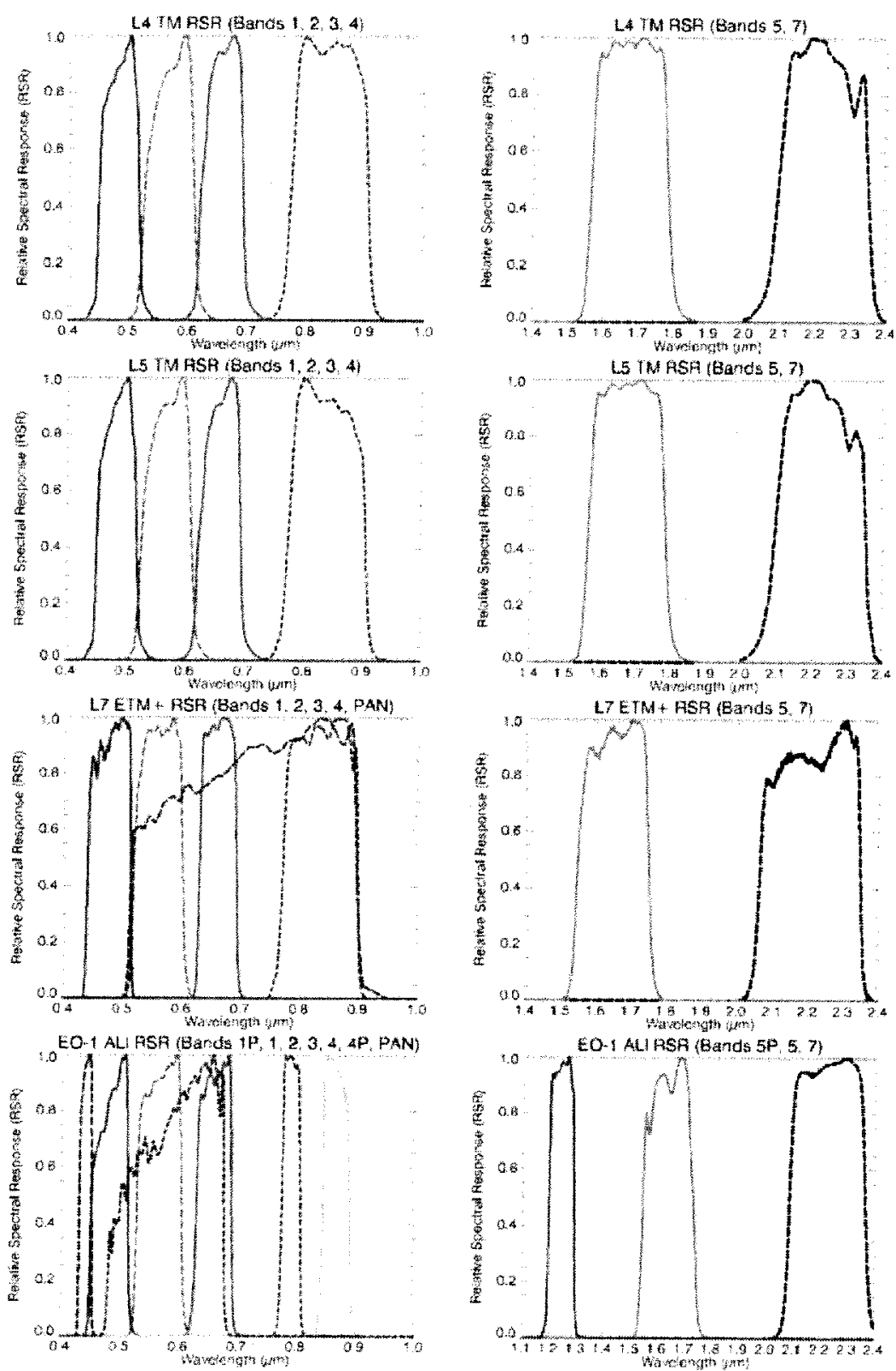

Fig. 2. Comparison of the solar reflective bands RSR profiles of $L 4 T M, L 5 T M, L 7 E T M+$, and EO-1 ALI sensors. 